\title{
The Research of Risk Management in Two Non-Independent IT System
}

\author{
Zhe Yin ${ }^{1,2}$, Yunfei Guo ${ }^{2}$, Maosheng Lai ${ }^{*}$ \\ ${ }^{1}$ Department of Information Management, Peking University, Beijing, China; ${ }^{2}$ Mathematics Department, Yanbian University, Yanbian, \\ China. \\ Email: yinzhe@ybu.edu.cn
}

Received March 30 ${ }^{\text {th }}, 2010$; revised April 30 th 2010 ; accepted May 31 $1^{\text {st }}, 2010$.

\begin{abstract}
Enterprises use IT system in business sector/information management sector and production management sector on purpose of the operation, which, of course, is inseparable from risk management. Two non-independent risk estimates functions are hence founded in order to receive the information of risk easily, that is, the cash flow-based evaluation functions. Applying the logarithmic probability-distribution function in the estimates function as well as giving an example by simulating, this essay has explained the affection of the uncertain factors to the enterprise management such as the business treatment and so on. At last, it has commented the application of the estimates function in the risk management.
\end{abstract}

Keywords: IT System, Non-Independent, Risk Management, Logarithmic Probability-Distribution Function

\section{Introduction}

The role of IT in business activities has been more and more important; besides, the amount of its investment is also increasing. The key of operating businesses more effectively is to base on the operating principles and to play the role of IT systems. The application of IT systems can not only apply to business operations and maintenance, but also to social services and business competition [1].

Japanese companies consulting firms Shigeru Inoue [2] 2000 , proposed that the key of risk management is enterprise risk quantification, so the introduction of IT systems need to use the reorganization of business structures [3], and through the systematic of business processes to achieve business strategy and IT systems integration and quantification of organic. UNISYS Corporation Toshiaki Otsuka [4] also proposed risk management should go through the entire IT system development, testing and operation cycle. When meeting a bad objective environment, not only should we reconstruct the system, but also give the risk management throughout the system life cycle.

In order to carry out the risk management of the changes in the external environment [5], this article deals only with a risk quantification, to determine the percentage of operating losses, and to reduce risk through information sharing. First, the cash flow-based evaluation function which can reflect the values of IT systems is embodied; and considered the effects of IT investments and risk prediction of two non-independent IT systems such as knowledge management systems and intelligence processing systems. Knowledge management systems are the IT systems of the operational management levels, while intelligent processing systems for of IT systems which are for the purpose of knowledge discovery, personalization-depth study of levels.

This article gives the logarithmic probability distribution function and proposes specific statistical methods of quantifying the risk. Ultimately, in order to adapt to social changes in the external environment, the application of the evaluation function in the risk management is also discussed.

\section{The Role of Information Sharing}

As a manager of IT systems, there is need to analyze business strategy and decision-making, and to determine the system operators who will invest in IT systems and operators who can increase efficiency of the systems through the application of IT systems. The system responsible for $\mathrm{CIO}$ and the CEO positions of different operators are unlikely to adopt the same evaluation systems. In order to fully share information, using the same assessment system and the introduction of discounted cash flow method [6] are the preferred methods of evaluation function. As the evaluation function, not only can 
it reflect their own business performance, but also accurately can it reflect the risks to the business environment. Therefore, in order to be prepared to risk, it is also necessary to venture into visual (through statistical tables and charts) besides quantifying, which can achieve a more intuitive result.

\section{The Cash-Flow Considered Evaluation Function}

In order to show the effect of IT systems, we introduce the evaluation function (the cumulative efficiency), which is composed of the IT investment costs, income and value-added.

$$
\begin{aligned}
F=-I+\sum_{t=1}^{T} & \{- \text { Cope }(t)+C R(t) \\
& +C G(t)\} \times f(r, t)+O p b+O p i
\end{aligned}
$$

where

I: construction costs of IT systems;

Cope $(t)$ : maintenance costs of IT systems;

$C R(t)$ : reduced costs within the enterprise;

$C G(t)$ : increased turnovers according to IT systems construction;

$T$ : lifetime of IT system;

$O p b$ : added value of improving the business environment;

Opi: reduction effect of business management risk;

$f(r, t)$ : function of the current conversion efficiency $(r=$ risk rate, $t=$ time);

The main idea of constructing evaluation function $\mathrm{F}$ is that the profit is equal to the difference between input and income. Besides, the risk rate will change with the change of the time .So $F$ is a dynamic function.

$$
\text { and } \quad f(r, t)=\frac{1}{(1+r)^{t}}
$$

When the purpose of IT investments in the market is to improve the enterprise's competitive edge, the system values is mainly in terms of increasing the value of the amount of $C G(t)$ and its business environment the added value of $O p b$. And when for the management purposes, the system performance in terms of cost reduction is in the amount of the value of $C R(t)$. When in order to improve the business environment or to lay a good foundation for business environment, importing IT systems to reduce costs or improve enterprise efficiency does not work at all.

The role of IT systems can be changed as the business environment to reduce $\mathrm{Opi}$ (risk reduction) as its necessity. The value of $O p b$, Opi and $t$ can be used as the reference variable of the business environment, which can be quantified by using options and other methods.

\section{An Empirical Analysis of Aisk Quantitative}

\subsection{Examples and Statistical Methods to Quantify the Risk}

Take medium-scale IT systems as an example, cost of the project A has been shown in Table 1. Initial development costs are 1 million yuan, annual maintenance costs are 150,000 yuan, the annual loss of initial cost is $30 \%$, an annual increase of turnover is $20 \%$, and value-added based on customer satisfaction is 100,000 yuan. Assuming that IT system life are 7 years, the investment benefit evaluation function (expression (1)) $=1.1253$ million yuan. Cost of the project B is shown in Table 2. There is no problem from quantity to consider, then how much will the risks be?

The risk of cumulative incremental value of operating benefits (expression (1)) can be expressed through the probability distribution function, according to Pareto distribution theory, cumulative incremental value of operating benefits meets the log-normal distribution. Suppose the best reduced cost per year of project $\mathrm{A}$ is 300,000 yuan, the minimum is 50,000 yuan, the maximum is 320,000 yuan, operational efficiency expectations is 200,000 yuan, the standard deviation is 50,000 yuan; he best reduced cost per year of project B is 200,000 yuan, the minimum is 65,000 yuan, the maximum is 250,000 yuan, operational efficiency expectations is 150,000 yuan, the standard deviation is 30,000 yuan, and the correlation coefficient of the two projects $r=-0.2$, the cumulative incremental value of operating benefits meets the log-

\begin{tabular}{|c|c|}
\hline Initial investment $I$ & 1 million yuan \\
\hline maintenance costs s /year Cope & 150,000 yuan \\
\hline reduced costs within the enterprise /year $C R$ & 300,000 yuan \\
\hline $\begin{array}{l}\text { increased turnovers according to IT } \\
\text { systems construction /year } C G\end{array}$ & 200,000 yuan \\
\hline risk rate $r(\%)$ & $5 \%$ \\
\hline $\begin{array}{l}\text { added value of improving the business } \\
\text { environment } O p b\end{array}$ & 100,000 yuan \\
\hline
\end{tabular}
normal distribution .

Table 1. Costing table of project A

\begin{tabular}{|c|c|}
\hline Initial investment II & 600,000 yuan \\
\hline maintenance costs s /year Cope & 100,000 yuan \\
\hline reduced costs within the enterprise /year $C R$ & 200,000 yuan \\
\hline $\begin{array}{l}\text { increased turnovers according to IT } \\
\text { systems construction / year } C G\end{array}$ & 150,000 yuan \\
\hline risk rate $r(\%)$ & $4 \%$ \\
\hline $\begin{array}{l}\text { added value of improving the business } \\
\text { environment } O p b\end{array}$ & 60,000 yuan \\
\hline
\end{tabular}

Table 2. Costing table of project $B$ 
According to expression (1), the 7-year total cumulative increment economic benefits of project $\mathrm{A}$ is 60,230 yuan, 160,748 yuan and 177,280 yuan respectively when the reduced cost of project A is 50,000 yuan, 300,000 yuan and 320,000 yuan, respectively, and the corresponding natural logarithm, is, respectively, $-1.79558,2.77725$ and 2.875145 . The standard deviation of normal distribution $\ln (5)=1.600$; the 7-year total cumulative increment economic benefits of project B is 5,514 yuan, 92,286 yuan and 126,143 yuan respectively when the reduced cost of project B is 65,000 yuan, 300,000 yuan and 320,000 yuan, respectively, and the corresponding natural logarithm, is $-0.5953,2.22$ and 2.5348 , respectively, The standard deviation of normal distribution $\ln (3)=$ 1.100 .

The logarithmic of cumulative incremental of economic benefits of project A in the interval [-1.79558, 2.875145] meets the normal distribution, and the logarithmic of cumulative incremental of economic benefits of project $\mathrm{B}$ in the interval $[-0.5393,2.5348]$ also meets the normal distribution. We need only to find the probability of color part in (Figures 1 and 2).

From

$$
\begin{aligned}
& p(x<u)=\Phi[(u-\mu) / \sigma], \\
& \Phi(u)=\frac{1}{\sqrt{2 \pi}} \int_{-\infty}^{u} e^{-t^{2} / 2} d t
\end{aligned}
$$

We can obtain

$$
\begin{aligned}
p(-1.79558<X<0)= & \{1-p(X<2.1590)\}- \\
& \{1-p(X<2.875145)\} \\
= & \{1-\Phi[(2.1590-1.0795) / 1.6]\}- \\
& \{1-\Phi[(2.875145-1.0795) / 1.6]\} \\
= & \{1-0.8686\}-\{1-0.9582\} \\
= & 0.0896
\end{aligned}
$$

Similarly, we can obtain

$$
\begin{aligned}
p(0.5393<Y<0) & =\Phi(1.234)-\Phi(0.7) \\
& =0.8888-0.758 \\
& =13.8 \%
\end{aligned}
$$

We can see that the probability that the logarithm of benefit evaluation function of project A takes a negative value is $8.96 \%$, that is, the probability of investment losses is $8.96 \%$; the probability that the logarithm of benefit evaluation function of project A takes a positive value is $91.04 \%$, that is not difficult to find the probability that investments can yield results is $91.04 \%$; the probability that the logarithm of benefit evaluation function of project B takes a negative value is $13.08 \%$, that is, the probability of investment losses is $13.08 \%$; the probability that the logarithm of benefit evaluation function of project $\mathrm{B}$ takes a positive value is $86.92 \%$, that is not difficult to find the probability that investment can bear fruit is $86.92 \%$.

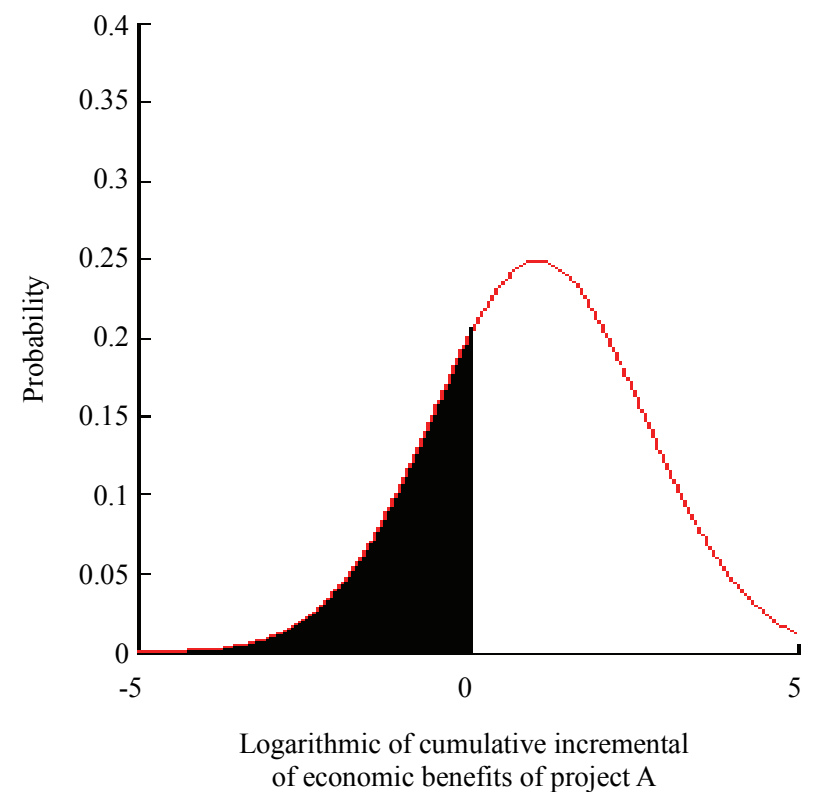

Figure 1. Normal distribution of project $A$

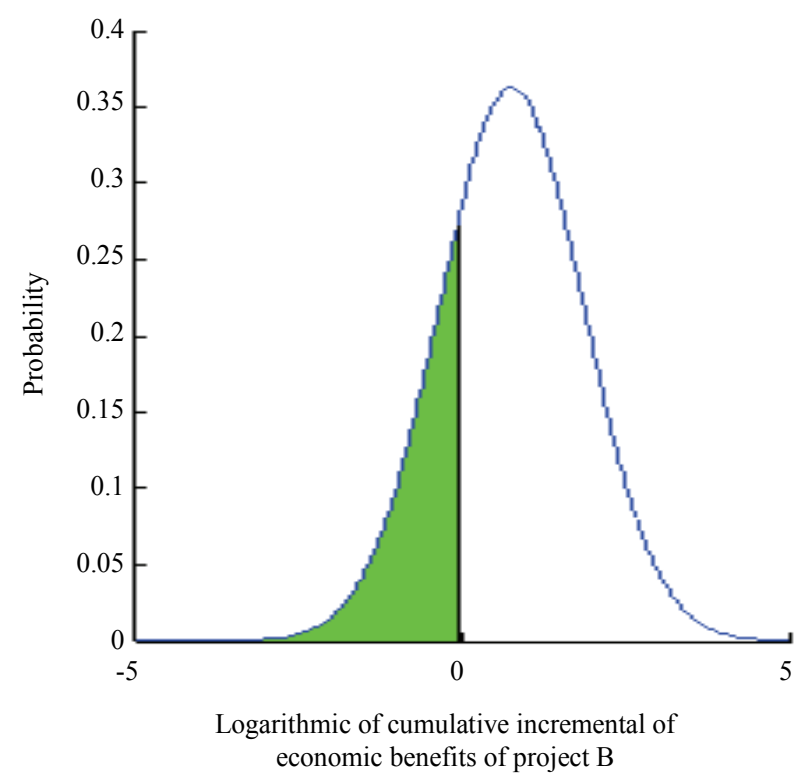

Figure 2. Normal distribution of project $B$

Finally, we proceed to study the risk of the two project, that is the risk situation of $X+Y$. The two projects A and $B$ are relevant, we can see that the pdf (probability density function) of $Z=X+Y$

$$
p_{Z}(x)=\frac{1}{\sqrt{2 \pi\left(\sigma_{X}^{2}+2 r \sigma_{X} \sigma_{Y}+\sigma_{Y}^{2}\right)}} e^{-\frac{(x-a-b)^{2}}{2\left(\sigma_{X}^{2}+2 r \sigma_{X} \sigma_{Y}+\sigma_{Y}^{2}\right)}},
$$

where $(X, Y) \sim N\left(a, b ; \sigma_{X}^{2}, \sigma_{Y}^{2} ; r\right)$ 


$$
\begin{aligned}
& \text { Since }(X, Y) \sim N\left(a, b ; \sigma_{X}^{2}, \sigma_{Y}^{2} ; r\right) \\
& p(x, y)=\frac{1}{2 \pi \sigma_{X} \sigma_{Y} \sqrt{1-r^{2}}} \times \\
& \exp \left\{-\frac{1}{2\left(1-r^{2}\right)}\right. \\
& \left.\left(\frac{(x-a)^{2}}{\sigma_{X}^{2}}-2 r \frac{(x-a)(y-b)}{\sigma_{X} \sigma_{Y}}+\frac{(y-b)^{2}}{\sigma_{Y}^{2}}\right)\right\} \\
& p_{Z}(x)=\frac{1}{2 \pi \sigma_{X} \sigma_{Y} \sqrt{1-r^{2}}} \times \\
& \int \exp \left\{-\frac{1}{2\left(1-r^{2}\right)}\right. \\
& \left.\left(\frac{(z-a)^{2}}{\sigma_{X}^{2}}-2 r \frac{(z-a)(x-z-b)}{\sigma_{X} \sigma_{Y}}+\frac{(x-z-b)^{2}}{\sigma_{Y}^{2}}\right)\right\} d z
\end{aligned}
$$

Let $v=x-a-b$ and $u=z-a$

We can obtain that

$$
\begin{gathered}
p_{Z}(x)=\frac{1}{2 \pi \sigma_{X} \sigma_{Y} \sqrt{1-r^{2}}} \times \\
\int \exp \left\{-\frac{1}{2\left(1-r^{2}\right)}\right. \\
\left.\left(\frac{u^{2}}{\sigma_{X}^{2}}-2 r \frac{u(v-u)}{\sigma_{X} \sigma_{Y}}+\frac{(v-u)^{2}}{\sigma_{Y}^{2}}\right)\right\} d u
\end{gathered}
$$

Besides

$$
\begin{aligned}
& \frac{u^{2}}{\sigma_{X}^{2}}-2 r \frac{u(v-u)}{\sigma_{X} \sigma_{Y}}+\frac{(v-u)^{2}}{\sigma_{Y}^{2}} \\
= & u^{2} \frac{\sigma_{X}^{2}+2 r \sigma_{X} \sigma_{Y}+\sigma_{Y}^{2}}{\sigma_{X}^{2} \sigma_{Y}^{2}}-2 u v \frac{\sigma_{X}+r \sigma_{Y}}{\sigma_{X} \sigma_{Y}^{2}}+\frac{v^{2}}{\sigma_{Y}^{2}} \\
= & {\left[u \frac{\sqrt{\sigma_{X}^{2}+2 r \sigma_{X} \sigma_{Y}+\sigma_{Y}^{2}}}{\sigma_{X} \sigma_{Y}}\right.} \\
& \left.-\frac{v}{\sigma_{Y}} \frac{\sigma_{X}+r \sigma_{Y}}{\sqrt{\sigma_{X}^{2}+2 r \sigma_{X} \sigma_{Y}+\sigma_{Y}^{2}}}\right]^{2} \\
& +\frac{v^{2}\left(1-r^{2}\right)}{\sigma_{X}^{2}+2 r \sigma_{X} \sigma_{Y}+\sigma_{Y}^{2}}
\end{aligned}
$$

Let

$$
\begin{gathered}
t=\frac{1}{\sqrt{1-r^{2}}}\left[u \frac{\sqrt{\sigma_{X}^{2}+2 r \sigma_{X} \sigma_{Y}+\sigma_{Y}^{2}}}{\sigma_{X} \sigma_{Y}}\right. \\
\left.-\frac{v}{\sigma_{Y}} \frac{\sigma_{X}+r \sigma_{Y}}{\sqrt{\sigma_{X}^{2}+2 r \sigma_{X} \sigma_{Y}+\sigma_{Y}^{2}}}\right]
\end{gathered}
$$

So

$$
p_{Z}(x)=\frac{\exp \left\{-\frac{v^{2}}{2\left(\sigma_{X}^{2}+2 r \sigma_{X} \sigma_{Y}+\sigma_{Y}^{2}\right)}\right\}}{2 \pi \sqrt{\sigma_{X}^{2}+2 r \sigma_{X} \sigma_{Y}+\sigma_{Y}^{2}}} \int e^{-\frac{t^{2}}{2}} d t
$$

Since $v=x-a-b$ and $\int e^{-\frac{t^{2}}{2}} d t=\sqrt{2 \pi}$

$$
p_{Z}(x)=\frac{1}{\sqrt{2 \pi\left(\sigma_{X}^{2}+2 r \sigma_{X} \sigma_{Y}+\sigma_{Y}^{2}\right)}} e^{-\frac{(x-a-b)^{2}}{2\left(\sigma_{X}^{2}+2 r \sigma_{X} \sigma_{Y}+\sigma_{Y}^{2}\right)}}
$$

So $E(X+Y)=E X+E Y=1.0795+0.7622=1.8417$

$$
\begin{aligned}
\sigma_{X+Y} & =\sqrt{\sigma_{X}^{2}+2 r \sigma_{X} \sigma_{Y}+\sigma_{Y}^{2}} \\
= & \sqrt{1.96-2 \times 0.2 \times 1.6 \times 1.1+1.21} \\
\approx & 1.57 \\
& \mathrm{p}(-2.39088<X+Y<0) \\
& =\Phi(2.70)-\Phi(1.17) \\
& =0.9965-0.8770 \\
& =11.95 \%
\end{aligned}
$$

\subsection{Result Analysis}

You can see risks reduce when the two projects relevant negatively from the above example, without considering the effects of environmental change, risk reduction $O P i$. Future research should take $O p i$ into account. In particular, with the case of the recent stock market volatility of the situation, the importance of risk management has received considerable attention. Risk management can be divided into the direct decision-making opportunities for risk management and indirect risk management whose profit has nothing to do with direct one. Both are closely linked into enterprise efficiency and business. The promotion of local management capacity can play through regional or global risk management into operations activities. As long as we handle of relations between local interests the global economic correctly, the objectives can be achieved by sharing resources, reducing risk, and the best operation and management purposes.

\section{Conclusions}

Investment in IT systems is the key to quantifying of the economic indicators during the application. Since the 
top-down management style, is very difficult to forecast the future assessment of corporate efficiency, this paper presents the loss probability calculation method of risk quantification and easily sharing of risk information method. (Figure 1, Figure 2) can play a function of profit and loss evaluation of the effectiveness of visualization. Future research purpose is the establishment of IT investsment and run-time system, real-time investment evaluation system in order to reduce investment risks.

\section{REFERENCES}

[1] R. L. Nolan and F. W. Mcfarlan, "Information Technology and the Board of Directors," Harvard Business Re- view, Vol. 83, No. 10, 2005, pp. 96-106.

[2] S. Inoue, "Risk Management," Unisys Technology Review, Vol. 67, No. 6, 2000, pp. 100-119.

[3] J. F. Sowa and J. A. Zachman, "Extending and Formalizing the Framework for Information Systems Architecture," IBM System Journal, Vol. 31, No. 3, 1992, pp. 590-616.

[4] T. Otsuka, "Software Testing Technology," Unisys Technology Review, Vol. 93, No. 8, 2007, pp. 70-88.

[5] J. Liu, "Introduction to Risk Management [M]," China Financial Press, Beijing, September 2005.

[6] T. L. Patton, J. F. Wang translated, "Enterprise Risk Management CFO Management \& AMP; Products [M]," China Renmin University Press, Beijing, 2007. 